\title{
PERAN KELUARGA KRISTEN BAGI PERTUMBUHAN IMAN ANAK \\ PADA MASA KINI
}

SURIANTI LAEN

Institut Agama Kristen Negeri Toraja

suriantilaen@gmail.com

\begin{abstract}
The role of the family is very important for the growth of children's faith, especially at this time in facing the times. It is highly expected for Christian families or parents to have a sufficient understanding of children's faith growth for the better, because in today's life the development of digitalization greatly affects children, especially their busy playing online games. Many things can be done by families to pay attention to faith growth for children, for example, instilling discipline in children, conveying God's Word to children from an early age, inviting them to diligently read the Bible, praying together, paying attention to religious education for children, both at church and at school, and the most important thing is the example of family faith. The process of children's faith growth is also influenced by communication in the family every day.
\end{abstract}

Keywords: Growth, Faith, Christian Family, Children, Exemplary

\begin{abstract}
Abstrak
Peran keluarga sangat penting bagi pertumbuhan iman anak, terutama pada masa kini dalam menghadapi perkembangan zaman. Sangat diharapkan bagi keluarga Kristen atau orang tua untuk memiliki pemahaman yang cukup dalam pertumbuhan iman anak untuk menjadi lebih baik, karena dalam kehidupan masa kini perkembangan digitalisasi sangat mempengaruhi anak-anak terutama kesibukan mereka bermain games online. Banyak hal yang dpat dilakukan keluarga untuk memperhatikan pertumbuhan iman bagi anak, misalnya, menanamkan kedisiplinan kepada anak, menyampaikan Firman Tuhan kepada anak sejak dini, mengajak untuk rajin membaca Alkitab, berdoa bersama, memperhatikan pendidikan agama bagi anak, baik di gereja maupun di sekolah, dan yang paling penting adalah keteladanan iman keluarga. Proses pertumbuhan iman anak juga dipengaruhi dari komunikasi dalam keluarga setiap hari.
\end{abstract}

Kata Kunci: Pertumbuhan, Iman, Keluarga Kristen, Anak, Keteladanan 


\section{A. Pendahuluan}

Salah satu harapan dan tujuan gereja adalah pertumbuhan iman Kristen, sehingga kehidupan krohanian setiap orang percaya diharapkan untuk senantiasa bertumbuh dan menjadi matang. Pertumbuhan iman seorang anak itu berarti tumbuh secara rohani untuk menjadi serupa denga Kristus. Hal inilah yang kemudian menjadi titik focus yang paling utama bago orang percaya. Kematangan kerohanian yang dimaksudkan yaitu pada bagian pemahaman mengenai doa, Firman, karakter, serta persekutuan dengan orang percaya. ${ }^{1}$

Peran keluarga sangat berpengaruh bagi pertumbuhan iman anak, sehingga sangat diperlukan sejak dini. Keluarga adalah bagian utama dalam pendidikan agama dan pertumbuhan iman sorang anak. Dalam menjalankan perannya, keluarga harus menjadi teladan sehimngga anak-anak dapat mengikuti hal yang baik yang diteladankan kepada mereka. Banyak hal yang perlu dilakukan keluarga untuk mendukung pertumbuhan iman anak, misalnya dimulai dari kumunikasi yang baik dalam keluarga, memperhatikan pertumbuhan iman bagi anak, menanamkan kedisiplinan kepada anak, menyampaikan Firman Tuhan kepada anak sejak dini, mengajak untuk rajin membaca Alkitab, berdoa bersama, memperhatikan pendidikan agama bagi anak, baik di gereja maupun di sekolah. Pendidikan agama di sekolah dan di gereja juga sangat mendukung usaha keluarga untuk meningkatkan pertumbuhan iman anak. Di dalam menjalankan peran, setiap keluarga tidak berhasil dengan mudah untuk mengontrol pertumbuhan iman anak karena dipengaruhi oleh banyak hal.

\section{B. Tujuan dan Manfaat}

Pada masa sekarang ini, keluarga sangat berperan penting dalam menentukan terjadinya pertumbuhan iman seorang anak. Jurnal ini ditulis bertujuan untuk memberikan beberapa penjelasan mengenai cara untuk menumbuhkan iman anak seperti memberikan keteladanan dalam hal berdoa, baca alkitab, kedisiplinan dan lain sebagainya.

Setelah kita mengerti dan memahami tentang cara-cara yang dapat dilakukan untuk membantu menumbuhkan iman seorang anak, maka sangat diharapkan proses pertumbuhan iman anak melalui keluarga akan jauh lebih efektif. Itulah manfaat dari jurnal ini ditulis, karena jurnal ini sudah memberikan pemahaman yang cukup baik tentang bagaimana cara agar iman seorang anak dapat bertumbuh dengan baik dalam keluarga.

\footnotetext{
${ }^{1}$ Mangiring Tua Togatorop, Septrianus Waruwu dan David Martinus Gulo, “Pola Asuh Keluarga Kristen Terhadap Pertumbuhan Iman Anak," Real Didache: Jurnal Teologi dan Pendidikan Agama Kristen (Maret 2020): 25.
} 


\section{Pembahasan}

Dalam Kamus Besar Bahasa Indonesia, Pertumbuhan berasal dari kata tumbuh, yang artinya timbul dan bertambah besar/sempurna, juga berarti berkembang atau memiliki kemajuan. Sedangkan kata Iman dalam KBBI artinya kepercayaan atau hal yang berkenan dengan agama, keyakinan kepada Allah, ketetapan hati, keteguhan batin, dan lain sebagainya. Kata anak juga dalam KBBI, berarti keturunan atau disebut manusia yang kecil. $^{2}$

Jadi, dapat disimpulkan bahwa, pertumbuhan Iman anak merupakan sebuah proses yang dilalui untuk mengembangkan atau memajukan imannya kepada Allah untuk mencapai tahap leboh baik dalam iman, kasih dan pengharapan kepada Allah. Pengenalan tentang Tuhan kepada anak-anak dimulai sejak kecil karena dalam menjalani kehidupan, jiwa dan rohani anak sangat penting untuk mengalami pertumbuhan iman. Pengenalan yang dilakukan sejak dini akan menjadi penunjang dalam bagi mereka untuk memasuki pengenalan akan hubungannya dengan Tuhan dan akan mendorong mereka untuk mengetahui lebih jauh tentang keberadaan dirinya. Pengajaran tentang Firman Tuhan yang dimulai dari dalam keluarga dapat mempermudah anak bertumbuh menjadi dewasa dalam iman dan kelak dapat menyikapi perubahan sikap yang menjadi kenyataan hidup imannya. Dalam memperhatikan pertumbuhan anak, keluarga harus memberikan penajaras dasar iman yang baik, supaya anak memiliki fondasi yang kokoh sebagai bangunan Allah dan iman anak akan bertumbuh dalam kehidupannya sikap iman yang bagus itu akan nampak. Sebagaimana dalam kitab Amsal 22 : 6 dikatakan bahwa "Didiklah orang muda menurut jalan yang patut baginya, maka pada masa tuanya pun ia tidak akan menyimpang dari pada

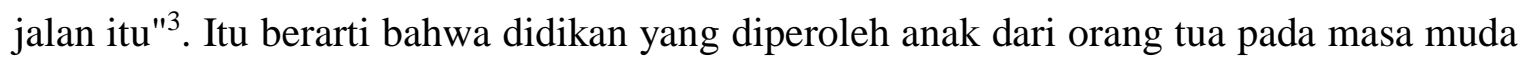
akan berperngaharuh terhadap kehidupan anak dikemudian hari. Orang tua harus mendidik anak dan mengarahkannya kepada jalan yang benar.

Dalam kehidupan anak-anak, mereka akan hidup menurut apa yang menjadi pengalaman atau yang dialami secara langsung. Kualitas kematangan pertumbuhan iman seseorang itu tergantung pada sedikit atau banyaknya latihan-latihan yang diupayakan oleh keluarga karena keluargalah yang menjadi dasar dalam perkembangan iman anak. ${ }^{4}$ Karena keluarga yang menjadi dasar utama pertumbuhan iman seorang anak, jadi keteladanan dari

\footnotetext{
${ }^{2}$ Departemen pendidikan dan kebudayaan, Balai Pustaka, Kamus Besar Bahasa Indonesia, Jakarta: Perum Penerbitan dan Percetakan Balai Pustaka; 1988.

${ }^{3}$ Amsal 22:6

${ }^{4}$ Ruth S. Kadarmanto, M.A, Tuntunlah ke Jalan Yang Benar (Jakarta: BPK Gunung Mulia, 2003), 29.
} 
dalam keluarga sangatlah penting. Anak-anak akan lebih cenderung melihat bagaimana perilaku orang tua mereka lalu meniru perilaku tersebut. Ketika peniruan anak berlangsung secara berulang-ulang atau terus-menerus, maka sikap peneladanan akan semakin kuat. Sebagian besar orang tua akan merasa senang jika anaknya mau menirukan perilakunya dan pujian bagi anakpun akan semakin mendorong anak untuk terus meniru teladan tersebut. Sikap peneladanan akan terjalin dengan baik ketika orang tua, guru, atau siapapun yang diteladani oleh anak-anak mau memberinya pujian. ${ }^{5}$ Keteladanan perbuatan baik keluarga atau orang tua akan menjadi pendorong bagi anak bahwa ia merasa diperhatikan dan disayang. Sementara itu, nasihat atau saran melalui kata-kata yang bijak dari orang tua akan akan menjadi motivasi bagi anak-anak. ${ }^{6}$

Selain memberi teladan keluarga atau orang tua harus menanamkan kedisiplinan bagi anak agar pertumbuhan iman anak dapat berjalan dengan baik. Alkitab memberi pelajaran pentingnya disiplin yang penuh dengan kasih. Orang tua yang tidak menanamkan kedisiplinan bagi anak akan merugikan bagi orang tua sendiri maupun bagi anak di kemudian hari. Penanaman nilai kedisiplinan bagi anak harus disesuaikan menurut perkembangan usia mereka tanpa paksaan. ${ }^{7}$ Dalam Alkitab, kata disiplin itu bermakna sebagai suatu ungkapan kasih dari orang tua kepada anak-anaknya. Artinya, orang tua diberi mandate untuk mendidik anak serta memberi latihan kepada mereka sesuai waktunya. $^{8}$

\section{KESIMPULAN}

Salah satu harapan dan tujuan gereja adalah pertumbuhan iman Kristen, sehingga kehidupan krohanian setiap orang percaya diharapkan untuk senantiasa bertumbuh dan menjadi matang. Peran keluarga sangat berpengaruh bagi pertumbuhan iman anak, sehingga sangat diperlukan sejak dini. Keluarga adalah bagian utama dalam pendidikan agama dan pertumbuhan iman sorang anak. Dalam menjalankan perannya, keluarga harus menjadi teladan sehingga anak-anak dapat mengikuti hal yang baik yang diteladankan kepada mereka. Selain itu, komunikasi dalam keluarga sangat penting juga terutama dalam penanaman pengetahuam tenntang Firman Allah dan pengajaran kedisiplinan menuju kehidupan yang lebih baik.

\footnotetext{
${ }^{5}$ Rannu Sanderan, "Exemplary Menemukenali Kunci Pendidikan Bagi Anak Dalam Keluarga dan Pembelajaran Agama di Sekolah," Jurnal PAK_Ganjil 3, no.1 (November2021) :4.

${ }^{6}$ Ibid, 9.

7 Ibid.

${ }^{8}$ Rannu Sanderan, “Disiplin Asketisme dan Harmoni Kontribusi Displin Diri bagi Pengembangan Pendidikan Kristen", Jurnal Pascasarjana PAK (November 2021), 7.
} 


\section{E. SARAN}

Dalam proses pertumbuhan Iman anak, keluarga merupakan bagian utama yang berperan di dalamnya. Untuk itu sangat diharapkan bagi keluarga atau orang tua anak untuk tetap memantau dan mendampingi anak menurut kehendak dan kasih Tuhan. 


\section{F. DAFTAR PUSTAKA}

Departemen pendidikan dan kebudayaan, Balai Pustaka, Kamus Besar Bahasa Indonesia, Jakarta: Perum Penerbitan dan Percetakan Balai Pustaka; 1988.

Kadarmanto,Ruth S., Tuntunlah ke Jalan Yang Benar. Jakarta: BPK Gunung Mulia, 2003.

Sanderan, Rannu, "Exemplary Menemukenali Kunci Pendidikan Bagi Anak Dalam Keluarga dan Pembelajaran Agama di Sekolah,” Jurnal PAK_Ganjil 3, no.1 (November2021) :4.

Sanderan, Rannu, "Disiplin Asketisme dan Harmoni Kontribusi Displin Diri bagi Pengembangan Pendidikan Kristen”, Jurnal Pascasarjana PAK (November 2021), 7.

Togatorop, Mangiring Tua, dkk, "Pola Asuh Keluarga Kristen Terhadap Pertumbuhan Iman Anak," Real Didache: Jurnal Teologi dan Pendidikan Agama Kristen (Maret 2020): 25. 